\title{
Treatment of aortic dissecting aneurysm involving visceral arteries with multi-layer bare stents
}

1. Department of Vascular Surgery, Tianjin Medical University General Hospital, Tianjin 300052 PR China 2. Department of General Surgery, Tinjin Huanghe Hospital, Tianjin 300101 PR China 3. Department of General Surgery, Tianjin Medical University General Hospital, Tianjin 300052 PR China

\section{SUMMARY}

OBJECTIVE: Aortic dissecting aneurysms involving visceral arteries are difficult for clinical treatment. This study aimed to explore the clinical efficacy and safety of multi-layer bare stents technique in the treatment of aortic dissecting aneurysms involving visceral arteries.

METHOD: The clinical data of 16 patients of aortic dissecting aneurysm involving visceral artery treated with multi-layer bare stents technique from March 2013 to March 2017 in Tianjin Medical University General Hospital were retrospectively analyzed. To explore the clinical efficacy, the number of stents applied, postoperative aortic dissecting thrombosis and postoperative cumulative branch arterial patency of the16 patients.

RESULTS: The operations of the 16 patients were successfully completed without peri-operative death cases. The 16 patients were implanted with 39 bare stents with an average of 2.44 per person. There were 2 cases with 1 stent, 8 cases with 2 stents and 7 cases with 3 stents. One month after the operation, CTA showed complete thrombosis in the arterial dissection in 4 cases (25.0\%), partial thrombosis in 12 cases (75.0\%); CTA showed that celiac artery, left and right renal arteries, and superior mesenteric artery were all unobstructed. There were 4 cases (25.0\%) of dissecting artery with reduced diameter, 12 patients (75.0\%) without changes in the diameter, and no diameter expanding cases.

CONCLUSION: The treatment for aortic dissecting aneurysm involving the visceral arteries using multi-layer bare stents technique is safe and reliable with a higher patency rate of postoperative accumulated branch arteries.

KEYWORDS: Aneurysm, dissecting. Aortic aneurysm. Stents. Endovascular procedures.

\section{INTRODUCTION}

Aortic dissection (AD) is a disease with a rapid onset and a dangerous prognosis. Aortic dissecting aneurysms involving visceral arteries are difficult for clinical treatment ${ }^{1,2}$. Conservative treatments of this disease have high risks, and there is high mortality after open surgery ${ }^{3}$. Traditional endovascular graft exclusion is a safe and effective method for aortic dissections that do not involve the visceral artery;

DATE OF SUBMISSION: 17-Apr-2018

DATE OF ACCEPTANCE: 27-May-2018

CORRESPONDING AUTHOR: Xiangchen Dai

Department of General Surgery, Tianjin General Hospital (The 1staffiliated hospital of Tianjin Medical University)

Tianjin 300052 PR China. No.154, Anshan Road, Heping District, Tianjin 300052 PR China.

E-mail: douxyi82@163.com 
however, dealing with aortic dissections involving important branches is very difficult ${ }^{4}$. How to reconstruct a vital branch artery is the key to solving this problem. After blocking the proximal crevasse, thoracic endovascular aortic repair (TEVAR) dramatically reduces mortality and the rate of complications. However, distal dissection cannot be cured. What is more, some cases develop into dissecting aneurysms involving abdominal visceral branch arteries. In this regard, the application of endovascular technology still faces significant challenges. Fenestration and the branch stents need space to expand the stent, but the true lumen of the dissection patient is often narrow, which makes the application of these two technologies limited. Also, part of the visceral arteries are from the false lumen of the dissecting aneurysm, so that the fenestration, branches, and parallel stent technology are more difficult to use. In recent years, the emergence of multi-layer bare stent technology for the treatment of dissecting aneurysms involving visceral branch arteries has brought hope ${ }^{5}$. Multi-layer bare stent technology has subverted the traditional concepts of traditional endovascular graft exclusion by regulating the blood flow and making dissection false lumen thrombosis while maintaining visceral artery patency ${ }^{6}$. Moreover, the technical difficulty has been dramatically reduced, so this is expected to become a safe, minimally invasive and effective method for the treatment of aortic dissecting aneurysms involving visceral arteries.
In this study, 16 patients with aortic dissecting aneurysm involving visceral arteries treated with multi-layer bare stent technique from March 2013 to March 2017 were retrospectively analyzed to study its short and mid-term efficacy.

\section{METHODS}

General information of the included patients

In this group, there were 16 patients aged 20-82 years old, including 13 males and 3 females. They were associated with symptoms of varying degrees of chest and back, waist or abdominal pain with the onset time 8h-10d. Computed tomography angiography (CTA) examination before the surgery showed aortic dissecting aneurysm involving visceral arteries (Figure 1). Among the 16 patients, there were 15 with hypertension, 3 with coronary heart disease, 1 with diabetes, 1 with nephrotic syndrome, 1 with Marfan syndrome, and 1 with Behcet's disease. Also, this was the first operation for 11 of the patients and reoperation for 5 of them.

\section{Surgical Procedure}

Under general anesthesia, the right (or left) common femoral artery was punctured using the Seldinger method; the puncture site was located below the midpoint of the line between the ipsilateral anterior superior iliac spine and the upper edge of the pubic symphysis. The $8 \mathrm{Fr}$ sheath was
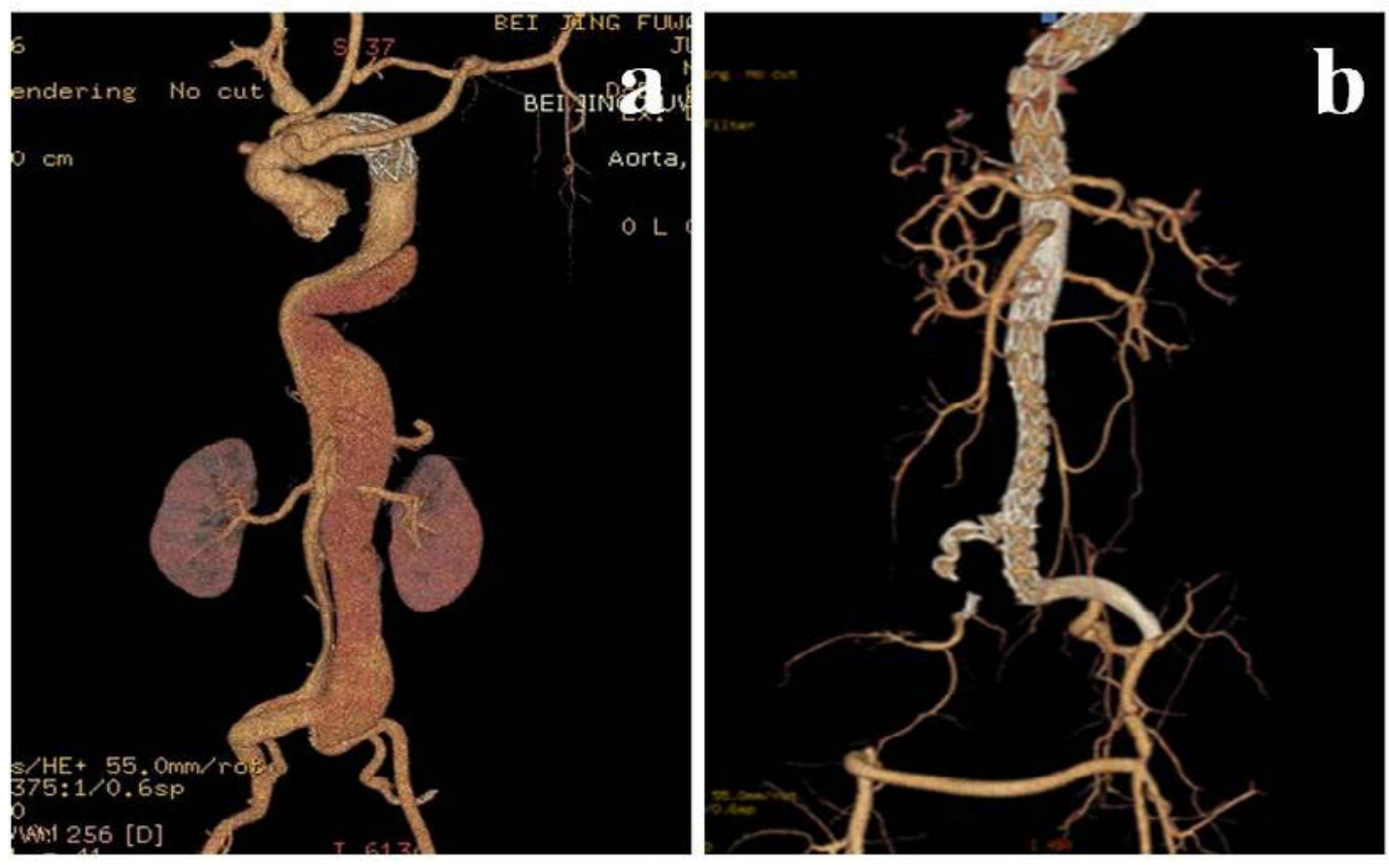

FIGURE 1

Computed tomography angiography (CTA) examination before and after the surgery showed aortic dissecting aneurysm involving visceral arteries(a: CT threedimensional vascular reconstruction of the thoracoabdominal aorta before surgery; b: Post-surgery thoracoabdominal aorta CT threedimensional vascular reconstruction) 


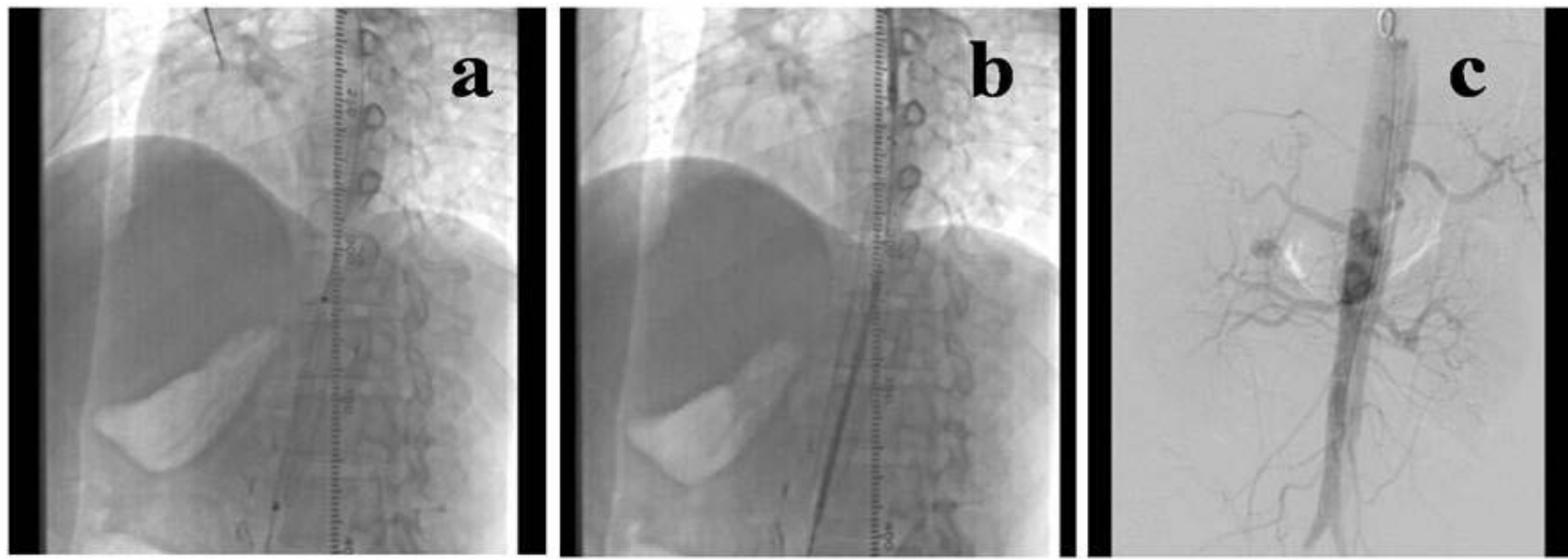

FIGURE 2. Endovascular treatment for aortic dissecting aneurysms (a: Bare stent covering the main visceral artery; b: BareStent covering non-visceral area dissection; c: Postoperative angiography of main visceral arteries patency.)

placed and heparin (80 IU / kg) administered in the sheath. The 0.035-inch ultra-smooth guide wire was led to reach the proximal end of the aortic lesion segment under the surveillance of digital subtraction angiography (DSA). 6Fr Pigtail catheter was exchanged with an injection rate of $20 \mathrm{ml} / \mathrm{s}$ and a total volume of $40 \mathrm{ml}$, aortic angiography was performed with the upper limit of 1000 psi injection pressure and the lesion location and size was re-determined. Puncture site sheath was changed for the 10Fr sheath, and the 0.035inch super-hard guide wire was guided to go across the aortic lesion segment. The guide wire was used to guide into the bare stents (Sinus-XL stent, Germany Optimed Company) one by one and overlap them over the lesion. The size of the stent was chosen to be about $10-20 \%$ of the diameter of the proximal neck of the aneurysm as described in the instructions. The proximal or distal end of the bare stent was extended to continuously place the covered stent in order to cover all the crevasses. The final number of bare stents depended on the results of intra-operative angiography, which is based on a slowdown in the flow rate of contrast media in the tumor cavity. The branches of the aorta, including CA, SMA, RA, and SA, were directly covered without revascularization or spinal cord protection. After the release of the stent, the guide wire catheter was removed, the puncture point was sutured using a vascular suture device, was the area was binded up with local pressurization (Figure 2).

\section{Statistical analysis}

The statistical analysis was performed by SPSS17.0 statistical software (http://www-01.ibm. com/software/analytics/spss/), the measurement data were expressed with $\bar{x} \pm s$, and the enumeration data were expressed with a relative number. $\mathrm{P}<0.05$ meant a statistical difference.

\section{RESULTS}

Stent application

Sixteen patients successfully completed the operation with a total of 39 bare stents (average of 2.44 per person). Also, there were 2 cases with 1 stent, 8 cases with 2 stents and 7 cases with 3 stents.

\section{Arterial dissection thrombosis}

All the patients received CT angiography (CTA) examination during 1-4 weeks after the operation to assess the arterial dissection thrombosis. CTA showed complete thrombosis in the arterial dissection in 4 cases (25.0\%) and partial thrombosis in 12 cases $(75.0 \%)$, (Figure 3 )

\section{The main branch arterial patency}

One to 4 weeks post-operation, the CTA showed that the celiac artery, left and right renal arteries and superior mesenteric artery were unobstructed.

Changes in the size of the dissection arterial diameter

CTA examination was performed one month after the surgery to assess the changes in the size of the dissection arterial diameter of patients, and the results showed that 4 cases had diameter reduction (25.0), 12 cases had no changes in diameter in (75.0\%), and there were no diameter expanding cases. 

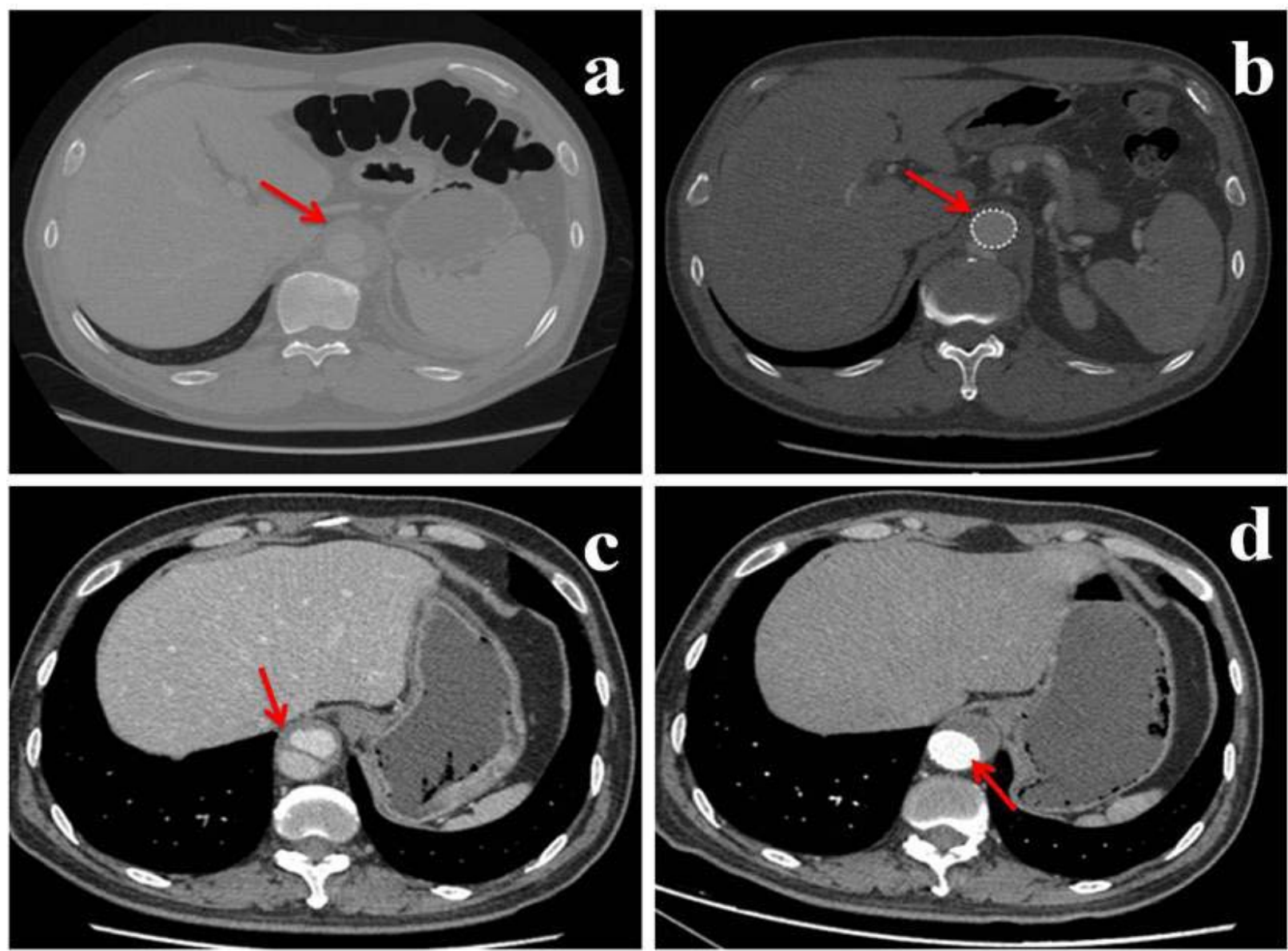

FIGURE 3. CT scan showed the arterial dissection thrombosis 1 to 4 weeks after operation (a: Dissecting aneurysm of abdominal aorta before surgery; b: Post-surgery, CT scan showed partial thrombosis; c: Dissecting aneurysm of abdominal aorta before surgery of another case; $d$ :Post-surgery, CT scan showed complete thrombosis)

\section{DISCUSSION}

Aortic dissecting aneurysm involving visceral branch arteries has been a challenge for endovascular graft exclusion ${ }^{7}$. The traditional covered stent also covers the adjacent important branch arteries together while isolating aneurysms, resulting in target organ ischemia, necrosis, and dysfunction ${ }^{6,8}$. In order to solve this problem, the branch/fenestrated stents (Zenith fenestrated endovascular graft) came into being. According to the important branch open position and angle shown by the patient's preoperative CTA image, fenestration must be performed in the corresponding position of the straight-type covered stent; the fenestration must be made toward each branch artery while releasing the stent. Then the branch stent must be placed through the fenestration position to both isolate the aneurysm and protect the patency of important branch arteries ${ }^{8}$. However, such complex surgical procedures and the individualization of the stent make this technology challenging to be performed in smaller medical institutions ${ }^{9}$. The fenestration and branch stents need space to expand, but the true lumen of the dissection patient is often narrow, which limits the application of these two techniques. Moreover, because part of the visceral arteries are from the false lumen of the dissecting aneurysm, the fenestration, as well as branch and parallel stent technologies, are more difficult to apply. The near or mid-term treatment effect of flat renal or suprarenal abdominal aortic dissecting aneurysm is good, but because its indications are strict, the requirements to the surgeon's experience and techniques are high, and stent customization costs a long time and much money too, so it cannot be popularized widely at present. There are no regular products of branch stents, but only some case reports about it. Also, chimney stent complications, such as leakage and stent compression occlusion and other problems, still plague clinical practice. The emergence of multi-layer bare stent technology to solve the problem of branch artery patency provides a new 
way of thinking. The objective of the covered stent is to build a mechanical barrier between the normal arterial lumen and the false lumen of the dissecting aneurysm cavity, and the multi-layer bare stent is designed to reduce the blood flow velocity and shear stress in the dissection, thereby inducing the formation of thrombosis in the dissection and achieving the "physiological" isolation, thus achieving the purpose of the treatment ${ }^{10}$. With the formation of thrombosis in the dissection, the shear stress of the arterial dissection wall is gradually reduced. At the same time, thrombosis increased the effective thickness of the wall and reduced the radius of the arterial lumen to achieve the effect of reducing the wall tension. However, bare stent-induced thrombosis is a relatively slow process. It may take several months to reach an effective level. During this period, the patient is still at risk of dissection fracture. In this study, CTA follow-ups 1 week and 1 month after the operation have found basic thrombosis in the dissection. There were no cases of dissection fracture. However, patients with hypertension should strictly control blood pressure to minimize the risk of dissection fracture while the thrombosis in the dissection has not yet fully formed.

In this present study, the maximal diameter of arterial dissection was reduced by $3.5 \mathrm{~mm}$ on average, and there were no complications such as dissection expanding and fracture. A previously published study ${ }^{4}$ reported using optimed bare stent multi-layer overlapping method for the treatment of 13 patients with dissecting aneurysms with an average follow-up of 20.9 months. The mean arterial diameter was reduced from $52.7 \mathrm{~mm}$ to $51.5 \mathrm{~mm}$, but this was not statistically significant. The false lumen of the dissecting aneurysm completed thrombosis in 12 months in only $16.7 \%$ of the patients. Analysis of the reasons for that showed that most of the aortic dissections have distal crevasses, the distal end of the false lumen has outflow tracts, and the blood forms a stable circulation method. Therefore, the simple implantation of multi-layer bare stents has poor efficacy. However, it has good efficacy for dissection patients without obvious outflow tracts in the distal thrombosis. In this study, all the patients received covered stents placed in the dissecting non-visceral blood vessels area to cover the dissection crevasses and destroy the stable laminar flows, and they were placed into the bare stents sequentially, to achieve a satisfactory therapeutic effect.
In our present study, the average number of bare stents used was 2.44, with a maximum of 3 and a minimum of 1 . Mainly based on the results of intra-operative angiography results, the number of bare stents stacked was flexibly controlled until the observed dissection blood flow velocity significantly decreased and the contrast agent density was significantly reduced. Thus the risk of incomplete isolation was greatly reduced. On the retention of the branch arteries, the short and middle term results of this study were satisfactory. No clinical symptoms of target organ ischemia were observed during the follow-up. There are also disagreements about postoperative anticoagulation therapy. In the literature ${ }^{11}$, postoperative routine combined with antiplatelet therapy (aspirin 100mg / d, clopidogrel $75 \mathrm{mg} / \mathrm{d}$ ) is recommended to maintain the patency of the branch arteries. However, antiplatelet therapy can delay the formation of thrombosis in the dissection, which is not conducive for reducing the risk of dissection fracture. In this study, routine antiplatelet therapy was not performed. For clinical effects, even if not given conventional antiplatelet therapy, branch arteries can still maintain good patency. This may be related to the "circulatory pathway" hypothesis that the blood flows go through the branch arteries into the target organ, and the corresponding venous flows go back to the heart, forming a closed circulatory system, which drives the blood flows to the branch arteries ${ }^{12}$.

\section{CONCLUSION}

In summary, the initial results of this study are satisfactory. However, some problems need to be further investigated. (1) How to determine the dissection prognosis during the surgery by the quantitative determination of DSA results; (2) how to deal with long-term arterial stenosis or occlusion in the stent coverage area is a matter of concern; (3) the current lack of multi-layer bare stent treatment norms and guidelines. Besides, the study was designed as a single center retrospective clinical study, and the number of cases included is relatively small. It is limited by the relatively short follow-up time. Moreover, long-term safety and effectiveness of multi-layer bare stent technology cannot be determined so far.

Declaration of conflict of interest: None 


\section{RESUMO}

Objetivo: Aneurismas dissecantes da aorta envolvendo artérias viscerais são de difícil tratamento clínico. O objetivo deste estudo foi explorar a eficácia e segurança clínica da técnica de stents multicamadas não farmacológicos para o tratamento de aneurismas dissecantes da aorta envolvendo artérias viscerais.

Métodos: Foi feito um estudo retrospectivo usando os dados de 16 pacientes com aneurisma dissecante da aorta envolvendo artérias viscerais e tratados com stents multicamadas não farmacológicos de março de 2013 a março de 2017, do Hospital da Escola de Medicina da Universidade de Tianjin. Foram analisados nos 167 pacientes: a eficácia clínica, o número de stents aplicados, trombose dissecante da aorta no pós-operatório e patência cumulativa pós-operatória do ramo arterial.

Resultados: As operações dos 16 pacientes foram concluídas com sucesso sem nenhum óbito perioperatório. Os 16 pacientes receberam 39 stents não farmacológicos, com uma média de 2,44 por indivíduo. Houve 2 casos com 1 stent, 8 com 2 stents, e 7 com 3 . Um mês após a operação, a ATC mostrou trombose completa da dissecção arterial em 4 casos $(25,0 \%)$ e trombose parcial em 12 casos (75\%). Também mostrou que a artéria celíaca, as artérias renais direita e esquerda e a artéria mesentérica superior estavam todas desobstruídas. Houve 4 casos (25,0\%) de artéria dissecante com diâmetro reduzido, 12 (75,0\%) pacientes sem alteração no diâmetro, e nenhum caso de aumento de diâmetro.

Conclusão: O tratamento para aneurisma dissecante da aorta envolvendo artérias viscerais com a técnica de stents não farmacológicos multicamadas é seguro e confiável, com uma taxa mais alta de patência de ramos arteriais acumulados no pós-operatório.

Palavras-chave: Aneurisma dissecante. Aneurisma da aorta. Stents. Procedimentos endovasculares.

\section{REFERENCES}

1 Kleiger R, Connors J, Avioli LV. Management of dissecting aortic aneurysm. Arch Intern Med. 1978;138(6):983-6.

2 Taylor JD, Dunckley M, Thompson M, Morgan RA. Endovascular management of chronic type $B$ dissecting aortic aneurysm utilizing aortic and renal stents. Cardiovasc Intervent Radiol. 2008;31(Suppl 2):S67-71.

3 Yamaguchi T, Kazui T, Inoue N, Ohno T, Komatsu S. Surgical management of abdominal aortic rupture in chronic dissecting thoracic aneurysm (DeBakey IIIb). Nihon Kyobu Geka Gakkai Zasshi. 1983;31(8):1320-4.

4 Zhang Y, Teng Z, Lu Q, Zhao Z, Bao J, Feng X, et al. Management of complicated aortic aneurysms using multiple overlapping uncovered stents: mid-term outcome from a cohort study. Medicine (Baltimore). 2014;93(27):e209.

5 Ke K, Zheng H, Yang W. Is multilayer bare stent safe or effective for the treatment of aortic aneurysms? A meta-analysis with early and mid-term outcomes. Ann Vasc Surg. 2017;40:112-9.

6 Zhang YX, Lu QS, jing ZP. Multilayer stents, a new progress in the endovascular treatment of aneurysms. Chin Med J (Engl). 2013;126(3):53641.
7 Nonami Y, Tomosawa N, Nishida K, Nawata S. Dissecting aortic aneurysm involving an anomalous right subclavian artery and isolated left vertebral artery: case report and review of the literature. J Cardiovasc Surg (Torino). 1998;39(6):743-6.

8 Katsargyris A, Oikonomou K, Klonaris C, Töpel I, Verhoeven EL. Comparison of outcomes with open, fenestrated, and chimney graft repair of juxtarenal aneurysms: are we ready for a paradigm shift? ] Endovasc Ther. 2013;20(2):159-69.

9 Zhang Y, Lu Q, Pei Y, Wu M, Zhang S, Hong Y, et al. Total endovascular repair of thoracoabdominal aortic aneurysms with non-customized stent grafts. Ann Thorac Surg. 2014;98(5):1606-12.

10 Sfyroeras GS, Dalainas I, Giannakopoulos TG, Antonopoulos K, Kakisis JD, Liapis CD. Flow-diverting stents for the treatment of arterial aneurysms. J Vasc Surg. 2012;56(3):839-46.

11 Matsco H. Aortic dissection, dissecting aortic aneurysm. Ryoikibetsu Shokogun Shirizu. 1996;(14):303-6.

12 Zhang YX, Lu QS, Feng JX, Zhao ZQ, Bao JM, Feng R, et al. Endovascular management of pararenal aortic aneurysms with multiple overlapping uncovered stents. J Vasc Surg. 2013;58(3):616-23. 